\title{
Emergency contraception use in young Norwegian women The role of social background, sexual history, and risk behaviors
}

Ingela Lundin Kvalem

University of Oslo

Ingrid Grov Mannsverk

Children and Youth's Services

WENDY NILSEN ( $\nabla$ wendy.nilsen@oslomet.no)

OsloMet - storbyuniversitetet Arbeidsforskningsinstituttet https://orcid.org/0000-0002-2982-0673

Research article

Keywords: Emergency contraception, young women, late adolescence, risk behavior

Posted Date: June 17th, 2020

DOI: https://doi.org/10.21203/rs.3.rs-30005/v1

License: () (1) This work is licensed under a Creative Commons Attribution 4.0 International License. Read Full License 


\section{Abstract \\ Background}

Emergency contraception use has received little attention compared to other contraceptives (e.g., condoms), despite increased use in most western countries. The present study aims to examine individual risk behavior and social characteristics of adolescent emergency contraception use of women in late adolescence, a key developmental stage for risky sexual behaviors.

\section{Methods}

A total of 214 young women (ages 18-20) from the community-based "Tracking Opportunities and Problems in Childhood and Adolescence" study self-reported their contraceptive use, sexual history (debut age, number of partners, sexually transmitted infections, abortions), risk behaviors (externalizing behavior, alcohol use), and social factors (living arrangements, educational status). Their mothers reported the young women's socioeconomic background (family economy, education). Differences were tested between groups that had never used emergency contraception, used it once, and used it many times.

\section{Results}

Over half of the sample had used emergency contraception. Emergency contraception users were a heterogeneous group. Multitime users of emergency contraception reported to have had more unprotected drunk sex than those having used emergency contraception once or never, and they were younger when they first had sexual intercourse and had more sexual partners (both in their lifetime and in the last year) than those who had never used emergency contraception. Emergency contraception use did not differ in relation to social background, regular contraception use, or consequences of unprotected sex.

\section{Conclusions}

This is one of the few studies examining characteristics of groups based on different types of emergency contraception use history in a community sample of women in their late adolescence. Findings revealed significant differences in the profiles of multi-time, one-time, and non-users of emergency contraception in some factors, but no difference between groups based on regular contraception use. The findings can provide researchers, practitioners, and policy makers with a more nuanced perspective of emergency contraception users, thus strengthening counseling and planning prevention efforts.

\section{Background}

According to the World Health Organization (WHO), adolescent fertility regulation and prevention of unintended pregnancies is one of the most important health-care issues of the 21 st century (1). A common explanation for unintended pregnancies is inconsistent or non-use of contraception. One of the most contemporary measures introduced to reduce unwanted adolescent pregnancies is easy access to contraception, such as prescription-free emergency contraceptive pills, or "morning after pills" (1). To reach sexually active young adult women, it is important to improve our knowledge about the users- and non-users of emergency contraception.

Research has regarded emergency contraception use as both a risk-taking and a responsible behavior $(2,3)$. For example, emergency contraception use has been found to typically not be used by those at risk of abortion (3), which could explain why increased emergency contraception sales has not been associated with a decrease in abortion rates. It is therefore of great importance to examine other characteristics associated with adolescent emergency contraception use.

The difficulty in identifying distinguishable patterns of contraceptive use may be related to the difference in sexual trajectories in adolescence (4), or that different motivations for use might have the same behavioral expression. For example, non-use of emergency contraception could be part of a consistent pattern of regular contraceptive use (because unprotected intercourse 
does not occur), but could also be part of a pattern of not using contraception at all. Measuring both regular and emergency contraception use could therefore expand earlier research on adolescent contraceptive patterns. Few studies have, however, studied and categorized the behavioral and social factors of both users and non-users of regular and emergency contraception.

The link between socioeconomic background and use of emergency contraception in adolescence is unclear. For example, high parental and individual education level was associated with more emergency contraception use both in a Norwegian (3), and a Dutch study (5). However, a large, population-based Finnish study, as well as a British study, found that high parental education was associated with less emergency contraception use $(6,7)$. Unregular family structure (e.g., not living in a nuclear family) has been linked with more use of emergency contraception as well (6).

Studies rarely distinguish between one-time and multiple use of emergency contraception, which might explain some contradictory findings. One-time emergency contraception use may represent different motivations and contraceptive patterns than multiple use does. By not measuring the frequency of use, it is possible that the heterogeneity of the emergency contraception users is overlooked.

In line with the problem-behavior theory (8), which posits that risk behaviors might appear in clusters due to underlying personality traits, research has found that problem behaviors (e.g., externalizing behavior, alcohol use) are linked with sexual risk behaviors (e.g., inconsistent contraceptive use) (9-12). Early sexual intercourse debut age and multiple sexual partners have often been understood as sexual risk behaviors (13). Early sexual initiation has been associated with multiple aspects of risk behavior, including inconsistent use of regular contraception, pregnancy, and a greater number of sexual partners $(14,15)$. As several studies have found that emergency contraception users report a higher total number of sexual partners $(2,16,17)$, it is reasonable to also expect an association of emergency contraception use with age at first sexual intercourse.

Alcohol use can be viewed as a risk behavior, and being intoxicated during intercourse has been associated with the use of emergency contraception use both among Norwegian (18) and Finnish women (6). In contrast, an older Swedish study did not find a strong direct link between alcohol use and emergency contraception use (19).

Norway has one of the highest emergency contraception pill consumption of the Nordic countries (20). In 2003, adolescent women (age 15-19) were estimated to use more than $50 \%$ of all emergency contraception pills sold in Norway (21). The research literature on emergency contraception use among adolescents is still scarce and often out-of-date, and findings are contradictory.

The main aim was to examine to which degree sexual history (intercourse debut age, number of partners, sexually transmitted infections, abortion), risk behaviors (externalizing behavior, alcohol use), and sociodemographic factors (own and mothers educational level, living arrangement, family economy) characterize emergency contraceptive versus regular contraceptive (oral contraceptives and condoms) users in young Norwegian women (ages 18-20). The second aim was to explore the differences between one-time and multi-time emergency contraception use.

\section{Methods}

\section{Design}

The current study used data from the Tracking Opportunities and Problems in Childhood and Adolescence (TOPP) study, a community-based longitudinal study of Norwegian children $(22,23)$. In 1993 , Norwegian mothers were recruited to participate when bringing the index child to a routine 18-month vaccination at a municipal child health center. In the first stage, 913 of 1,081 invited families participated (response rate $84 \%$ ). The 19 health care areas included in the TOPP study were representative of the overall diversity of communities in Norway; $28 \%$ of the families lived in large cities, $55 \%$ in small towns, and $17 \%$ in rural areas) (23).

The study was approved by The Data Inspectorate and the Regional Committee for Medical Research Ethics (\#S-04167). Study participants did not give written or oral informed consent, as that was not a requirement at the time of data collection. This is a requirement today, and the Regional Committee for Medical Research Ethnics in Norway have approved the study without 
informed consent (\#S-04167/\#2013/2052), due to respondents being given written information before and after each data collection about 1) Current and future research findings and topics; 2) The confidentiality of the participants; 3 ) The possibility to skip questions, and 4) The right to withdraw from the study at any point. All analyses for the current paper used anonymous cross-sectional data from the final wave (T8) in late adolescence/young adulthood (ages 18-20).

\section{The sample}

The current study included young women aged 18-20 $(n=295)$ participating in 2011, when the TOPP questionnaires involved sexual history and sexual risk behaviors. Of the participants, 216 of the 295 (73.2\%) reported to have had heterosexual vaginal intercourse. Two cases were removed from the sample due to inconsistent or missing responses, leading to a sample of 214 young women.

\section{Attrition}

Data from the health clinics showed that non-responding mothers did not differ from responding mothers in maternal age, education, employment status, or marital status when joining the study (23). Multiple logistic analyses of adolescent participation showed that female gender and high maternal education predicted young adult participation in 2011 (24). Variables such as maternal age, living with the father, maternal work status, and the family's financial situation did not predict young adult participation at 2011. The associations between variables at baseline compared to the last waves of the study did not differ among drop-out versus remaining families, suggesting that estimated associations between variables are generalizable (25).

\section{Measurement}

Experience and frequency of emergency contraception use was measured with the question "Have you ever used emergency contraception?" with the response alternatives "Have not used" (0) and "Have used" (1), and the follow-up question: "If so, how many times?" The response was used either as a continuous variable or categorized as: "Never used" (0), "Used once" (1), and "Used two or more times"(2) (19).

Use of regular contraception in the past year was measured by one question: "During the past 12 months, which type(s) of contraception have you/your partner used?" with the possibility to tick one or several response alternatives: "No contraception," "Condom," "Oral contraceptives/contraceptive injection," "Other types," and "I don't know." Responses of "Other types" and "I don't know" were excluded from further analysis. A new categorical variable was constructed: "Consistency of regular contraceptive use the past year," with three possible responses: "No use" (0), "Inconsistent use" (1) (ticked both No contraception and one or more of the methods of regular contraception), and "Consistent use" (2) (ticked of any kind of contraceptive method and did not tick No contraception).

Use of contraception during last intercourse was measured by the question: "At last intercourse, which type(s) of contraception did you/your partner use?" with the same response alternatives as the question about the past year. A categorical variable of contraceptive use at last intercourse was computed as "Non-use"(0) or "Use" (1).

Participants were also asked if they had ever had unprotected intercourse/sex without condoms or any other contraceptives while drunk ("Never" (0) "Once" (1), or "Two or more times" (2)).

Sexual history included self-reports about intercourse debut age, total number of sexual partners, number of sexual partners the past year, abortion, and sexually transmitted infections (STIs). The question of STIs was formulated as follows: "Have you ever received treatment for a sexually transmitted infection (venereal disease) such as chlamydia, herpes, genital warts or similar?"

\section{Risk behaviors.}

Externalizing behavior was measured with the TOPP Scale on Antisocial Behavior (TSAB; 24). The TSAB consists of 13 items mapping domains of externalizing behavior, partly based on the model by Loeber et al. (26), and items from other Scandinavian scales (27-29). Items covered actions one had done or participated in during the past year (e.g., shirked school or work, been in a 
fight, taken money from someone in one's family without permission, stolen, or tried marihuana). Responses were rated on a 5point Likert scale from "Not done it" (0) to "Done it more than 10 times" (4). Cronbach's alpha for TSAB in this study was 0.68 . A high mean score indicated more externalizing (antisocial) behavior the past year.

Alcohol use was measured by the Alcohol Use Disorder Identification Test (AUDIT; 30), in order to identify excessive drinking and risky consumption (31). The use of AUDIT in the adolescent population aged 14 to 18 is supported by research (32). Items were rated on Likert scales in which higher response categories equaled drinking in higher frequencies and more units. In the current study, only the total sum of scores was calculated, and a high mean score indicated more or less hazardous alcohol use. The internal consistency in this study was a $=.79$.

\section{Sociodemographic factors.}

Educational attainment was measured by asking if participants attended or had finished any education program, such as "General studies at high school," "Vocational high school," "One to two years of higher education," "Three years at college or university," or "Four or more years at university college or university."

Nine possible living arrangements were re-categorized into three possible responses: "Live with mother and father" (1), "Live with one parent/move between parents" (2), and "Live alone or with other than parents"(3).

Maternal education (maternal reports) was categorized as "High school or less"(0) and "Higher education" (1).

Family economy (maternal reports). The four response alternatives were "We manage very poorly," "We manage poorly," "We manage," "We are well off." These were re- categorized as "Poor or OK" (0) and "Good" (1).

\section{Statistical analysis}

Descriptive statistics using cross-tabulation with chi-square test, and correlations (Pearson's $r$ ) between study variables were obtained. Effect size criteria used for correlations were as follows: between 0.10 and 0.30 , small; $0.30-0.50$, medium; >0.50, large (33). A series of two-way between-groups analyses of variance (ANOVA) were carried out to examine the difference between groups within regular contraception users and emergency contraception users.

\section{Results}

Most of the young women had their sexual debut at age 16 or later $(56.5 \% ; 121 / 214)$ The median number of total sex partners was three, and the median for the past year was one. A minority reported a total of 10 or more lifetime sexual partners $(12.8 \% ; n$ $=27$ ), having been pregnant $(5.2 \% ; n=11)$, having had an abortion $(4.2 \% ; n=9)$, and having been treated for an STI (9.8\%; $n=$ $21)$. About half of the participants reported emergency contraception use $(52.3 \%, n=113)$. Of the emergency contraception users, $47.8 \%$ ( $n=54$; i.e., $25 \%$ of the total sample) had used emergency contraception only once, and $52.2 \%(n=59 ;$ i.e., $27 \%$ of the total sample) were multi-time users (i.e., more than one-time use). A small proportion $(8.8 \%, n=10 ; 4.6 \%$ of the total sample) had used emergency contraceptives 4-10 times. Most of the 216 adolescent women reported to be consistent users of regular contraception, including during the past year (87.6\%), at the time of last intercourse (88.7\%), and when drunk (72.4\%).

The distribution of maternal and adolescent characteristics, contraceptive behavior, abortion, and STIs across the emergency contraception use groups is presented in Table 1.

Table 1. Distribution of sociodemographic characteristics and sexual history on emergency contraception use in young women 


\begin{tabular}{|c|c|c|c|c|c|}
\hline & \multicolumn{5}{|c|}{ Emergency contraception use } \\
\hline & Never & Once & Twice or more & & \\
\hline & $\%(n)$ & $\%(n)$ & $\%(n)$ & $\chi^{2}$ & $\varphi / \varphi_{\mathrm{c}}$ \\
\hline Education status $(n=207)$ & & & & 5.39 & \\
\hline Vocational high school & $19.4(19)$ & $18.9(10)$ & $7.2(4)$ & & \\
\hline General studies at high school/higher education & $80.6(79)$ & $81.1(43)$ & $92.8(52)$ & & \\
\hline Maternal educational attainment $(n=164)$ & & & & 4.83 & \\
\hline High school or less & $53.7(44)$ & $36.8(14)$ & $36.4(16)$ & & \\
\hline Higher education & $46.3(38)$ & $63.2(24)$ & $63.6(28)$ & & \\
\hline Family economy $(n=159)$ & & & & 0.34 & \\
\hline Poor or OK & $48.1(39)$ & $42.9(15)$ & $48.8(21)$ & & \\
\hline Good & $51.9(42)$ & $57.1(20)$ & $51.2(22)$ & & \\
\hline Living arrangements $(n=216)$ & & & & 2.90 & \\
\hline With mother and father & $51.5(53)$ & $50.0(27)$ & $45.8(27)$ & & \\
\hline With one parent/move between parents & $25.2(26)$ & $27.8(15)$ & $37.3(22)$ & & \\
\hline Live alone or with other than parents & $23.3(24)$ & $22.2(12)$ & $16.9(10)$ & & \\
\hline \multicolumn{6}{|l|}{ Contraceptive behavior } \\
\hline Contraceptive use last intercourse $(n=211)$ & & & & 0.10 & \\
\hline No & $11.2(11)$ & $13.0(7)$ & $11.9(7)$ & & \\
\hline Yes & $88.8(87)$ & $87.0(47)$ & $88.1(52)$ & & \\
\hline Contraceptive use past year $(n=209)$ & & & & 3.03 & \\
\hline None & $5.0(5)$ & $3.8(2)$ & $1.8(1)$ & & \\
\hline Inconsistent & $6.1(6)$ & $11.3(6)$ & $12.3(7)$ & & \\
\hline Consistent & $88.9(88)$ & $84.9(45)$ & $85.9(49)$ & & \\
\hline Unprotected while intoxicated $(n=214)$ & & & & $24.63^{* * *}$ & .24 \\
\hline Never & $84.3(86)$ & $57.4(31)$ & $65.5(38)$ & & \\
\hline Once & $11.8(12)$ & $33.3(18)$ & $13.8(8)$ & & \\
\hline Twice or more times & $3.9(4)$ & $9.3(5)$ & $20.7(12)$ & & \\
\hline \multicolumn{6}{|l|}{ Consequences of unprotected sex } \\
\hline Abortion $(n=215)$ & & & & 1.89 & \\
\hline No & $97.1(99)$ & $92.6(50)$ & $96.6(57)$ & & \\
\hline Yes & $2.9(3)$ & $7.4(4)$ & $3.4(2)$ & & \\
\hline Sexually transmitted infection $(n=215)$ & & & & 6.55 & \\
\hline No & $94.1(96)$ & $81.5(44)$ & $91.5(54)$ & & \\
\hline Yes & $5.9(6)$ & $18.5(10)$ & $8.5(5)$ & & \\
\hline
\end{tabular}

Note. ${ }^{* * *} p \leq .001 . \varphi$ Effect size measure 'phi' for $2 \times 2$ contingency tables. $\varphi_{c}$ Effect size measure 'Cramer's V' for nominal and ordinal relations in larger contingency tables. Maternal reports on own education level and family economy was measured in 2006-2008. All other variables were self-reported by young women in 2011 .

Multi-time users of emergency contraception reported to have had more unprotected drunk sex $(p<.001)$ than those having used emergency contraception once or never, with effect sizes ranging from small to medium. The frequency of emergency contraception use did not differ in relation to sociodemographic background, living arrangements, contraceptive use, or consequences of unprotected sex. 
Table 2. Descriptive statistic, and correlations (Pearson's $r$ ) between regular/emergency contraception use with independent continuous variables

\begin{tabular}{|c|c|c|c|c|c|c|c|}
\hline & & & & \multicolumn{2}{|c|}{$\begin{array}{l}\text { Regular contraceptive use the past } \\
\text { year }\end{array}$} & \multicolumn{2}{|c|}{$\begin{array}{l}\text { Emergency contraception use (\# times } \\
\text { used) }\end{array}$} \\
\hline & Range & $\mathrm{M}(\mathrm{SD})$ & $\mathrm{n}$ & $\mathrm{r}$ & $r^{2}$ & $\mathrm{r}$ & $r^{2}$ \\
\hline Family economy & 4 & $\begin{array}{l}2.49 \\
(0.57)\end{array}$ & 159 & $0.27^{* *}$ & 0.07 & -0.02 & 0.00 \\
\hline Externalizing behaviors & 24 & $\begin{array}{l}5.98 \\
(4.66)\end{array}$ & 211 & $-0.20^{* *}$ & 0.04 & 0.16 & 0.03 \\
\hline Sexual debut age & 8 & $\begin{array}{l}15.77 \\
(1.41)\end{array}$ & 215 & -0.02 & 0.00 & $-0.19^{* *}$ & -0.04 \\
\hline Total number of sex partners & 25 & $\begin{array}{l}4.72 \\
(4.52)\end{array}$ & 211 & -0.15 & 0.02 & $0.34^{* *}$ & 0.12 \\
\hline $\begin{array}{l}\text { Number of sex partners the past } \\
\text { year }\end{array}$ & 11 & $\begin{array}{l}2.29 \\
(1.95)\end{array}$ & 210 & $-0.19^{* *}$ & -0.04 & $0.21^{* *}$ & 0.04 \\
\hline
\end{tabular}

Note. ${ }^{* *} p \leq .01$. Maternal reports of family economy was measured in 2008. All other variables self-reported by young women in 2011

\section{Associations between study variables and regular and emergency contraception use}

Correlations between independent variables and regular contraception use are presented in Table 2 . Having a good family economy $(r=.27 ; p<.01)$, less externalizing behaviors $(r=-.20 ; p<.01)$, and a lower number of sexual partners during the past year $(r=-.19 ; p<.01)$, were associated with more consistent use of regular contraception. A different pattern emerged for emergency contraception use, in which younger sexual debut age $(r=-.19 ; p<.01)$ and higher number of sexual partners (in total: $r=.34 ; p<.01$, and during the past year: $r=.21 ; p<.01$ ) were associated with more frequent use of emergency contraception.

Table 3 about here 
Table 3

Comparison of means (ANOVA) between emergency contraception groups and regular contraception groups

\begin{tabular}{|c|c|c|c|c|c|c|c|c|c|c|c|c|c|c|}
\hline & \multicolumn{7}{|c|}{ Emergency contraceptive use } & \multicolumn{7}{|c|}{ Regular contraceptive use the past year } \\
\hline & \multirow{2}{*}{\multicolumn{2}{|c|}{$\begin{array}{l}\text { Group 1: } \\
\text { Never used }\end{array}$}} & \multirow{2}{*}{\multicolumn{2}{|c|}{$\begin{array}{l}\text { Group 2: } \\
\text { Used once }\end{array}$}} & \multirow{2}{*}{\multicolumn{2}{|c|}{$\begin{array}{l}\text { Group 3: } \\
\text { Twice or } \\
\text { more }\end{array}$}} & \multirow[b]{3}{*}{$\mathrm{F}$} & \multirow{2}{*}{\multicolumn{2}{|c|}{$\begin{array}{l}\text { Group 4: } \\
\text { Never use }\end{array}$}} & \multirow{2}{*}{\multicolumn{2}{|c|}{$\begin{array}{l}\text { Group 5: } \\
\text { Inconsistent } \\
\text { use }\end{array}$}} & \multirow{2}{*}{\multicolumn{3}{|c|}{$\begin{array}{l}\text { Group 6: } \\
\text { Consistent } \\
\text { use }\end{array}$}} \\
\hline & & & & & & & & & & & & & & \\
\hline & $\mathrm{n}$ & $\begin{array}{l}M \\
\text { (SD) }\end{array}$ & $\mathrm{n}$ & $\begin{array}{l}M \\
\text { (SD) }\end{array}$ & $\mathrm{n}$ & $\begin{array}{l}M \\
(S D)\end{array}$ & & $\mathrm{n}$ & $\begin{array}{l}M \\
(S D)\end{array}$ & $\mathrm{n}$ & $\begin{array}{l}M \\
\text { (SD) }\end{array}$ & $\mathrm{n}$ & $\begin{array}{l}M \\
\text { (SD) }\end{array}$ & $\mathrm{F}$ \\
\hline $\begin{array}{l}\text { Externalizing } \\
\text { behavior }\end{array}$ & 100 & $\begin{array}{l}5.58 \\
(4.27)\end{array}$ & 54 & $\begin{array}{l}5.65 \\
(4.38)\end{array}$ & 57 & $\begin{array}{l}7.00 \\
(5.44)\end{array}$ & 1.88 & 8 & $\begin{array}{l}10.38 \\
(8.58)\end{array}$ & 19 & $\begin{array}{l}6.95 \\
(4.92)\end{array}$ & 177 & $\begin{array}{l}5.70 \\
(4.30)\end{array}$ & 4.45 \\
\hline Alcohol use & 97 & $\begin{array}{l}9.85 \\
(5.23)\end{array}$ & 53 & $\begin{array}{l}9.17 \\
(4.02)\end{array}$ & 55 & $\begin{array}{l}11.53 \\
(5.17)\end{array}$ & 3.38 & 8 & $\begin{array}{l}10.25 \\
(8.60)\end{array}$ & 19 & $\begin{array}{l}11.79 \\
(6.13)\end{array}$ & 171 & $\begin{array}{l}10.06 \\
(4.56)\end{array}$ & 1.05 \\
\hline Debut age $^{1}$ & 102 & $\begin{array}{l}16.05 \\
(1.42)\end{array}$ & 54 & $\begin{array}{l}15.83 \\
(1.46)\end{array}$ & 59 & $\begin{array}{l}15.22 \\
(1.18)\end{array}$ & $6.91^{* \star \star}$ & 8 & $\begin{array}{l}15.50 \\
(2.00)\end{array}$ & 19 & $\begin{array}{l}16.16 \\
(1.26)\end{array}$ & 181 & $\begin{array}{l}15.74 \\
(1.41)\end{array}$ & 0.89 \\
\hline $\begin{array}{l}\text { Total number } \\
\text { of sex } \\
\text { partners }\end{array}$ & 100 & $\begin{array}{l}3.43 \\
(3.29)\end{array}$ & 53 & $\begin{array}{l}5.08 \\
(4.42)\end{array}$ & 58 & $\begin{array}{l}6.60 \\
(5.66)\end{array}$ & $8.95^{\star \star \star}$ & 8 & $\begin{array}{l}7.50 \\
(7.82)\end{array}$ & 19 & $\begin{array}{l}5.89 \\
(4.18)\end{array}$ & 177 & $\begin{array}{l}4.57 \\
(4.39)\end{array}$ & 2.20 \\
\hline $\begin{array}{l}\text { Sex partners } \\
\text { the past year }\end{array}$ & 100 & $\begin{array}{l}1.92 \\
(1.57)\end{array}$ & 53 & $\begin{array}{l}2.53 \\
(2.12)\end{array}$ & 57 & $\begin{array}{l}2.70 \\
(2.27)\end{array}$ & 3.56 & 6 & $\begin{array}{l}3.67 \\
(3.60)\end{array}$ & 19 & $\begin{array}{l}3.21 \\
(2.35)\end{array}$ & 179 & $\begin{array}{l}2.22 \\
(1.79)\end{array}$ & 3.78 \\
\hline $\begin{array}{l}\text { Emergency } \\
\text { contraceptive } \\
\text { use }\end{array}$ & - & - & - & - & - & - & - & 8 & $\begin{array}{l}0.50 \\
(0.76)\end{array}$ & 19 & $\begin{array}{l}1.63 \\
(1.89)\end{array}$ & 182 & $\begin{array}{l}0.97 \\
(1.30)\end{array}$ & 2.66 \\
\hline
\end{tabular}

\section{Externalizing behavior, alcohol use, sexual debut age, and number of sex partners}

Table 3 shows the difference in externalizing behavior, alcohol use, sexual debut age, total number of sexual partners, and number of partners in the past year across the different emergency and regular contraceptive use groups. There was no statistical difference between the three emergency contraception groups regarding externalizing behavior, alcohol use, and number of partners in the last year. Multiple-time users of emergency contraception reported a younger sexual debut age ( $F(2$, $215)=6.91, p<.001)$ and a higher total number of sexual partners $(F(2,211)=8.95, p<.001)$ than the group who had never used emergency contraception.

There were no statistical differences in externalizing behavior, alcohol use, sexual debut age, or number of sex partners between the three regular contraception groups. Because the group who reported not using any regular contraception in the past year was very small $(n=8)$, the differences between two more balanced groups of contraception users (non/inconsistent use vs. consistent use) were tested with the same variables with $t$-tests. The results from the t-test showed no significant group differences (results not shown).

\section{Discussion}

The current study aimed to examine to what degree sexual history, risk behaviors, and sociodemographic factors characterize emergency and regular contraceptive use in young women aged 18-20. We found that emergency contraceptives were common among young adult women in Norway, and the findings indicated that emergency contraception users were a heterogenous group with a different risk factor pattern from regular contraceptive users. 
First, our findings showed that regular contraception is widely used by young women in Norway. Around half of the young women in the study reported having used emergency contraception, and about half of these women had used it more than once. The prevalence of emergency contraception use was similar to what was found in a Swedish study of university students (54\%; 34) and in a Norwegian study of middle adolescents in 2001 (52\%; 35), and it was somewhat higher than what was found among young adults in 1998-2005 (34\%; 3). In comparison, according to the Norwegian Institute of Public Health (36) there was a general increase in the sale of emergency contraception doses in the time period between these older studies and our data collected in 2011, whereas there was a decrease in the following years from 2011-2019.

Second, emergency contraception users were a heterogeneous group, with a somewhat different risk profile than regular emergency contraception users. While more consistent regular contraception use was associated with less externalizing behavior and better family economy, more frequent emergency contraception use was associated with younger sexual debut age and higher total number of sex partners. Despite these differences, the two groups also overlapped (e.g., $51.6 \%$ of the consistent regular contraception users the past year also reported having used emergency contraception at least once in their lifetime). However, one caveat is that we lack information on the timing of emergency contraceptive use, and it is thus possible that this occurred when the women were younger, and their regular contraceptive use was more inconsistent. Even so, there was a small correlation between a higher number of sexual partners in the past year with both less consistent use of regular contraception in the past year, and more frequent emergency contraception use. These findings indicate that the association between number of sexual partners and contraceptive behavior occurred relatively recently. A possible explanation might be that inconsistent users change partners frequently and therefore have many "first time" sexual encounters, which former studies have found are often unprotected $(37,38)$.

Third, our findings highlight the importance of distinguishing between one-time and multi-time users of emergency contraception. Multi-time users reported significantly higher incidences of unprotected intercourse under the influence of alcohol, with a higher number of sexual partners, and with a younger sexual debut age. These findings are in line with both a Belgian and Finnish study $(17,39)$, but contrary to a Swiss study $(37)$, which found no differences in sexual risk behaviors between one-time and multi-time users. A possible explanation for more sexual risk behavior in multi-time users is that adolescents use emergency contraception more often shortly after sexual debut, before they become efficient users of regular contraceptives (40). For example, a study by Chilman (41) found that inconsistent use of regular contraception was normal in the 6-12 months after sexual debut. Another explanation might be that younger sexual debut age expresses a plurality of sexual risk behaviors, such as multiple sexual partners, which might still be ongoing in late adolescence (41). There may also be differences in adolescent girls' psychological profiles that could explain our findings. A recent study by Jimenéz-Iglesias et al. (42) reported no differences between non- and one-time users of emergency contraception, but found life satisfaction to be higher in one-time users, while depression was higher in multi-time users.

Fourth, our findings supported the notion that emergency contraception use may reflect a responsible behavior. For instance, emergency contraception use (versus non-use) was not associated with a history of abortion or STIs in our study, an association which has been reported in several other studies (see e.g. 16, 19, 39, 43). Our findings were in line with a previous study from Norway (44), as well as a recent study from Spain (42) in which the authors concluded that one-time users had good psychological resources that allowed them to make effective decisions in important moments (regarding contraception and preventing pregnancy). It is possible that societal norms that accept adolescents as sexually active as long as pregnancy is prevented (e.g., as has been found in Nordic countries), will include emergency contraception use as a responsible behavior (45). Still, the relationship between psychological resources, abortion, STIs, and emergency contraception use needs to be explored further.

We found that education level, family economy, and living arrangements did not significantly differ between users and non-users of emergency contraception, and that emergency contraception users were not more frequently drinking or partaking in externalizing behaviors. In contrast, there was a link between a cluster of risk factors (poorer family economy, more externalizing behavior, and more sex partners) and inconsistent use of regular contraception. Former studies have suggested that externalizing behaviors (use of illicit drugs, aggression) are precursors to or in a cluster of other risk-taking behaviors (e.g., less contraception use) $(46,47)$, or a part of a norm-breaking behavior as suggested by the problem behavior theory. The difference in 
risk behaviors and family background between regular and emergency contraception users suggests that the latter group is represented by a different risk factor cluster compared to the regular contraception users.

Non- and one-time users of emergency contraception and consistent regular contraception users were the largest groups in our study sample, and despite some differences, they overlapped to a great extent. Of the consistent regular contraception users, more than half had used emergency contraception at least once in their life and often after having unprotected drunk sex. The results indicate that emergency contraceptive use does not replace regular contraceptive use, which has been a concern (34). Rather, the findings support the notion reported in several studies (46-48) that many young women tend to become more consistent regular contraception users after having used emergency contraception once.

The finding that adolescent consistent users of regular contraception occasionally have taken risks (e.g., had unprotected drunk intercourse or used emergency contraception) give nuance to strict categorizations such as "use" versus "non-use," and "risktaker" versus "responsible" $(2,3,42)$. To summarize, young adult women seem to protect themselves from pregnancy to a great extent, and want to be "better safe than sorry."

\section{Strengths and Limitations of the Current Study}

The current study fills a gap in the research field by examining characteristics of regular and emergency contraception use in late adolescence and early adulthood. By measuring the use of contraception in the past year and total, rather than only at latest intercourse, as well as one-time and multiple use of emergency contraception, we get a more comprehensive picture of contraceptive use in young adult women. There are, however, also limitations that must be considered.

Poor recall, social desirability bias, and post hoc justification may have impacted the responses on regular contraception consistency. Previous findings indicate that individuals tend to overestimate their adherence to an oral contraceptive regimen ((49). In addition, there was a lack of the timing and contextualization of emergency contraception use in our questions (e.g., whether use was after first intercourse, when in a relationship or single, when sober or drunk, or the gender and characteristics of the partner). For instance, previous Nordic studies suggest that having an older sexual partner is associated with more frequent emergency contraception use $(6,18,43)$.

Motivation for use and non-use of regular and emergency contraceptives was also not included (e.g., trying to become pregnant or not). However, the participants are in their late adolescence and young adulthood, so only a minor percentage might be planning to conceive.

\section{Clinical and research implications}

Future research should include emergency contraception use to comprehensively examine contraceptive behavior. Using detailed categorizations of contraceptive use (e.g., one-time versus multiple use of emergency contraceptives) might help explain and nuance the inconsistent results from previous research.

Political initiatives should be taken to prevent social inequality in adolescent health. A Norwegian report found that supplying young women with contraceptives free of cost increased the consistent use of regular contraceptives and bridged a great proportion into user-independent contraceptives (e.g., contraceptive implants). The rate of unprotected intercourse, abortions and emergency contraception use decreased (50). Former studies have found that limited access to emergency contraception was a barrier of use (51), so in order to simplify access, it should be possible to acquire emergency contraception online. Online provision of emergency contraception may be more convenient and less embarrassing for adolescents and enhance the safe use of this time-sensitive contraception (52).

\section{Conclusion}

This is one of few studies about the link between adolescent emergency contraception use and both individual and sociodemographic risk factors. A noteworthy result is that emergency contraception is a commonly used method among young 
adult women, and users are not a homogenous group. Findings revealed significant differences in the profiles of multi-time, onetime, and non-users of emergency contraception on some factors (e.g., in sexual debut age and number of sex partners), but no group difference in the consistency of regular contraception use. This implies that emergency contraception users might be both "saints" (i.e., conscientiousness-driven one-time users with less risky sexual behavior) and "sinners" (i.e., multi-time users driven by former risky sexual behavior), underscoring the need for more studies to include emergency contraception when studying contraceptive behavior. The current study has important implications, suggesting that future research should also longitudinally examine barriers to safe sex and pregnancy prevention for female adolescents.

\section{Abbreviations}

ANOVA

Analysis of Variance

AUDIT

Alcohol Use Disorder Identification Test

STI

Sexual transmitted infection

TOPP

Tracking Opportunities and Problems in Childhood and Adolescence

TSAB

TOPP Scale on Antisocial Behavior

WHO

World Health Organization

\section{Declarations}

Ethics approval and consent to participate

The study was approved by The Data Inspectorate and the Regional Committee for Medical Research Ethics (\#S-04167). Study participants did not give written or oral informed consent, as that was not a requirement at the time of data collection. This is a requirement today, and the Regional Committee for Medical Research Ethnics in Norway have approved the study without informed consent (\#S-04167/\#2013/2052), due to respondents being given written information before and after each data collection about 1) Current and future research findings and topics; 2) The confidentiality of the participants; 3) The possibility to skip questions, and 4) The right to withdraw from the study at any point. All analyses for the current paper were conducted on anonymous data.

Consent for publication

Not applicable

Availability of data and materials

Restrictions apply to the availability of these data, which were used under license for the current study, and so are not publicly available. The data can be found at secure servers at the Norwegian Institute of Public Health, and are protected under confidentiality laws and cannot be shared or passed on to anyone who is not authorized by the Norwegian Institute of Public Health for access to the data. Some of the variables used and/or analyzed during the current study might however be available in anonymized versions, from the corresponding author on reasonable request.

Competing interests

The authors declare that they have no competing interests

Funding

Page $11 / 14$ 
Authors' contributions

All authors conceptualized the research questions. IGM analyzed and interpreted the data the data, ILK and WN contributed in interpreting the data. ILK, IGM, and WN contributed in writing and revising the manuscript. WN participated in designing the surveys used for the current study. All authors read and approved the final manuscript.

Acknowledgements

This research is based on data from the Tracking Opportunities and Problems (TOPP) belonging to the Norwegian Institute of Public Health. We acknowledge all the participating families and their voluntary effort, as well as the health care personnel who contributed with the data collection. We acknowledge the founder of the TOPP-study, Dr. Kristin S. Mathiesen and all other researchers in the TOPP-group who contributed with the data collection. We also thank The Research Council of Norway, which have been the main contributor for funding the data collections.

\section{References}

1. Corbelli J, Bimla Schwarz E. Emergency contraception: a review. Minerva Ginecol. 2014;66(6):551-64.

2. Black KI, Mercer $\mathrm{CH}$, Johnson AM, Wellings K. Sociodemographic and sexual health profile of users of emergency hormonal contraception: data from a British probability sample survey. Contraception. 2006;74(4):309-12. doi:10.1016/j.contraception.2006.05.067

3. Pedersen W. Nødprevensjon eller abort? En longitudinell studie av unge kvinner. [Emergency contraception or abortion? A longitudinal study of young females.] Tidsskr Nor Laegeforen. 2007;127(24):3206-8. Retrieved from http://tidsskriftet.no/sites/tidsskriftet.no/files/pdf2007-3206-8.pdf

4. de Graaf H, Vanwesenbeeck I, Meijer S, Woertman L, Meeus W. Sexual trajectories during adolescence: Relation to demographic characteristics and sexual risk. Arch Sex Behav. 2009;38(2):276-82. doi:10.1007/s10508-007-9281-1

5. Van Lee L, Picavet C, Wijsen C. Emergency or precaution? Background and risk profiles of users of the Emergency Contraceptive. Utrecht: Rutgers Nisso Groep 4; 2006.

6. Falah-Hassani K, Kosunen E, Shiri R, Rimpela A. Emergency contraception among Finnish adolescents: awareness, use and the effect of non-prescription status. BMC Public Health. 2007;7:201. doi:10.1186/1471-2458-7-201

7. Whittaker PG, Berger M, Armstrong KA, Felice TL, Adams J. Characteristics associated with emergency contraception use by family planning patients: a prospective cohort study. Perspect Sex Reprod Health. 2007;39(3):158-66. doi:10.1363/3915807

8. Jessor R. Problem-behavior theory, psychosocial development, and adolescent problem drinking. Br J Addict. 1987;82(4):331-42. doi:10.1111/j.1360-0443.1987.tb01490.x

9. Caminis A, Henrich C, Ruchkin V, Schwab-Stone M, Martin A. Psychosocial predictors of sexual initiation and high-risk sexual behaviors in early adolescence. Child Adolesc Psychiatry Ment Health. 2007;1(1):14. doi:10.1186/1753-2000-1-14

10. Brodbeck J, Bachmann MS, Croudace TJ, Brown A. Comparing growth trajectories of risk behaviors from late adolescence through young adulthood: an accelerated design. Dev Psychol. 2013;49(9):1732-8. doi:10.1037/a0030873

11. Cooper ML, Wood PK, Orcutt HK, Albino A. Personality and the predisposition to engage in risky or problem behaviors during adolescence. J Pers Soc Psychol. 2003;84(2):390-410. doi:10.1037//0022-3514.84.2.390

12. Shawe J, Ineichen B, Lawrenson R. Emergency contraception: Who are the users? J Fam Plann Reprod Health Care. 2001;27(4):209-12. doi:10.1783/147118901101195777

13. Epstein M, Bailey JA, Manhart LE, Hill KG, Hawkins JD. Sexual risk behavior in young adulthood: broadening the scope beyond early sexual initiation. J Sex Res. 2014;51(7):721-30. doi:10.1080/00224499.2013.849652

14. Finer LB, Philbin JM. Sexual initiation, contraceptive use, and pregnancy among young adolescents. Pediatrics. 2013;131(5):886-91. doi:10.1542/peds.2012-3495

15. Sneed CD. Sexual risk behavior among early initiators of sexual intercourse. AIDS Care. 2009;21(11):1395-400. doi:10.1080/09540120902893241

Page 12/14 
16. Goulard H, Bajos N, Job-Spira N. [Emergency contraception in France: the user profile]. Gynecol Obstet Fertil. 2003;31(9):7249. doi:10.1016/s1297-9589(03)00208-x

17. Kuortti M, Kosunen E. Risk-taking behaviour is more frequent in teenage girls with multiple sexual partners. Scand J Prim Health Care. 2009;27(1):47-52. doi:10.1080/02813430802691933

18. Guleria S, Juul KE, Munk C, Hansen BT, Arnheim-Dahlstrom L, Liaw KL, et al. Contraceptive non-use and emergency contraceptive use at first sexual intercourse among nearly 12000 Scandinavian women. Acta Obstet Gynecol Scand. 2017;96(3):286-94. doi:10.1111/aogs.13088

19. Tyden T, Wetterholm M, Odlind V. Emergency contraception: the user profile. Adv Contracept. 1998;14(4):171-8. doi:10.1023/a:1006604214517

20. Lindh I, Skjeldestad FE, Gemzell-Danielsson K, Heikinheimo O, Hognert H, Milsom I, et al. Contraceptive use in the Nordic countries. Acta Obstet Gynecol Scand. 2017;96(1):19-28. doi:10.1111/aogs.13055

21. Dommerud T. Angrebølge blant unge jenter. [Wave of regret among young girls]. Dagens Medisin. 2003 March 13.

22. Nilsen W, Kjeldsen A, Karevold EB, Skipstein A, Sand Helland M, Gustavson K, et al. Cohort profile: The Tracking Opportunities and Problems Study (TOPP)-study of Norwegian children and their parents followed from infancy to early adulthood. Int J Epidemiol. 2017;46(5):1399-g. doi:10.1093/ije/dyx057

23. Mathiesen KS, Tambs K, Dalgard OS. The influence of social class, strain and social support on symptoms of anxiety and depression in mothers of toddlers. Soc Psychiatry Psychiatr Epidemiol. 1999;34(2):61-72. doi:10.1007/s001270050113

24. Kjeldsen A, Janson H, Stoolmiller M, Torgersen L, Mathiesen KS. Externalising behaviour from infancy to mid-adolescence: Latent profiles and early predictors. J Appl Dev Psychol. 2014;35(1):25-34. doi:10.1016/j.appdev.2013.11.003

25. Gustavson K, von Soest T, Karevold E, Roysamb E. Attrition and generalizability in longitudinal studies: findings from a 15year population-based study and a Monte Carlo simulation study. BMC Public Health. 2012;12:918. doi:10.1186/1471-245812-918

26. Loeber R, Wung P, Keenan K, Giroux B, Stouthamer-Loeber M, Van Kammen WB, et al. Developmental pathways in disruptive child behavior. Dev Psychopathol. 1993;5(1-2):103-33. doi:10.1017/S0954579400004296

27. Bendixen $M$, Olweus $D$. Measurement of antisocial behaviour in early adolescence and adolescence: psychometric properties and substantive findings. Crim Behav Ment Health. 1999;9(4):323-54. doi:10.1002/cbm.330

28. Mahoney JL, Stattin H. Leisure activities and adolescent antisocial behavior: the role of structure and social context. J Adolesc. 2000;23(2):113-27. doi:10.1006/jado.2000.0302

29. Rossow I, Bø AK. Metoderapport for datainnsamlingen til Ung i Norge 2002 [Methodological report on the data collection of "Young in Norway" 2002]. Oslo: Norwegian Social Research; 2003.

30. Babor TF, Higgins-Biddle JC, Saunders JB, Monteiro MG. AUDIT : the Alcohol Use Disorders Identification Test : guidelines for use in primary health care. Geneva: World Health Organization; 2001.

31. Halkjelsvik T, Storvoll EE. Andel av befolkningen i Norge med et risikofylt alkoholkonsum målt gjennom Alcohol Use Disorders Identification Test (AUDIT). Nordic Studies on Alcohol and Drugs. 2015;32(1):61-72. doi:10.1515/nsad-2015-0008

32. Knight JR, Sherritt L, Harris SK, Gates EC, Chang G. Validity of brief alcohol screening tests among adolescents: a comparison of the AUDIT, POSIT, CAGE, and CRAFFT. Alcohol Clin Exp Res. 2003;27(1):67-73.

doi:10.1097/01.Alc.0000046598.59317.3a

33. Cohen J. Statistical power analysis for the social sciences. Hillsdale, NJ: Lawrence Erlbaum; 1988.

34. Larsson M, Tyden T. Increased sexual risk taking behavior among Swedish female university students: repeated crosssectional surveys. Acta Obstet Gynecol Scand. 2006;85(8):966-70. doi:10.1080/00016340600626941

35. Breidablik HJ, Meland E. Ungdom og seksualitet i Utkant-Norge 1997-2001. [Youth and sexuality in rural Norway 19972001] Tidsskr Nor Laegeforen. 2004;124(13-14):1769-71.

36. Health TNloP. Nedgangen i salet av nødprevensjon held fram. [The decrease in the sale of emergency contaception is continuing] Oslo: The Norwegian Institute of Public Health; 2019. Available from: https://www.fhi.no/nyheter/2019/nedgangen-i-salet-av-nodprevensjon-held-fram/. 
37. Ottesen S, Narring F, Renteria SC, Michaud PA. Emergency contraception among teenagers in Switzerland: a cross-sectional survey on the sexuality of 16- to 20-year-olds. J Adolesc Health. 2002;31(1):101-10. doi:10.1016/s1054-139x(01)00412-8

38. Day WC. It 's your future - A look at young people around the world and their attitudes towards sex and contraception. A review of survey data gathered between 2009 and 2011. Berlin: Bayer Health Care; 2012.

39. Verhoeven $V$, Peremans $L$, Avonts $D$, Van Royen $P$. The profile of emergency contraception users in a chlamydia prevalence study in primary care in Belgium. Eur J Contracept Reprod Health Care. 2006;11(3):175-80. doi:10.1080/13625180600766289

40. Johnson AM, Wadsworth J, Wellings K, Field J. Sexual attitudes \& lifestyles Oxford: Blackwell Scientific Publications; 1994.

41. Chilman CS. Teenage pregnancy: a research review. Social Work. 1979;24(6):492-8. doi:10.1093/sw/24.6.492

42. Jimenez-Iglesias A, Moreno C, Garcia-Moya I, Rivera F. Prevalence of emergency contraceptive pill use among Spanish adolescent girls and their family and psychological profiles. BMC Womens Health. 2018;18(1):67. doi:10.1186/s12905-0180560-x

43. Sorensen MB, Pedersen BL, Nyrnberg LE. Differences between users and non-users of emergency contraception after a recognized unprotected intercourse. Contraception. 2000;62(1):1-3. doi:10.1016/s0010-7824(00)00128-1

44. Myrhaug HT, Nesheim BI, Kirkehei I, Juvkam KH, Havelsrud K, Egeberg K, et al. Easy access of hormonal contraceptives to women - age 20 to 24 years old. Oslo, Norway: Knowledge Centre for the Health Services at The Norwegian Institute of Public Health (NIPH); 2008.

45. Træen B, Lewin B, editors. Sexuality in context. Oslo: Universitetsforlaget; 2008.

46. Harper CC, Cheong M, Rocca CH, Darney PD, Raine TR. The effect of increased access to emergency contraception among young adolescents. Obstet Gynecol. 2005;106(3):483-91. doi:10.1097/01.AOG.0000174000.37962.a1

47. Kosunen E, Sihvo S, Hemminki E. Knowledge and use of hormonal emergency contraception in Finland. Contraception. 1997;55(3):153-7. doi:10.1016/S0010-7824(97)00022-X

48. Keogh LA. A qualitative study of women's use of emergency contraception. J Fam Plann Reprod Health Care. 2005;31(4):288-93. doi:10.1783/jfp.31.2.288

49. Potter L, Oakley D, de Leon-Wong E, Canamar R. Measuring compliance among oral contraceptive users. Fam Plann Perspect. 1996;28(4):154-8. doi:10.2307/2136191

50. Øren A, Leistad L, Haugan T. Endres prevensjonsvaner og abortrate hos kvinner 20-24 år ved tilbud om gratis hormonell prevensjon? [Do contraceptive habits and abortrates among females 20-24 years change when hormonal contraceptives free of cost are provided?]. Oslo: SINTEF; 2010.

51. Hovland K, Hagberg G. Nødprevensjon: Er informasjonen til ungdom god nok? [Emergency contraception: Is information to youth satisfactory?]. Oslo: University of Oslo; 2007.

52. Smith NK, Cleland K, Wagner B, Trussell J. "I don't know what I would have done." Women's experiences acquiring ulipristal acetate emergency contraception online from 2011 to 2015. Contraception. 2017;95(4):414-8.

doi:10.1016/j.contraception.2016.10.004 